\title{
LA ÉTICA: UN PROBLEMA PARA EL ODONTÓLOGO
}

\author{
Jorge Triana Estrada*
}

Resumen: El presente trabajo pretende crear conciencia entre los profesionales de la salud y las instituciones formadoras de odontólogos, acerca del riesgo de pérdida de credibilidad ante la sociedad de nuestro ejercicio profesional, así como informar de las principales causas de inconformidad de los pacientes derivadas de la ausencia de aplicación de preceptos éticos.

Palabras clave: credibilidad, bioética, preceptos

\section{ETHICS: A PROBLEM FOR ODONTOLOGISTS}

Abstract: This work pretends to awake consciousness, both in health professionals and in odontology teaching institutions, about the risk of loss of credibility facing professional practice. It also aims to inform about the main causes of patients' disagreement due to the absence of ethical rules.

Key Words: credibility, bioethics, precepts

\section{A ÉTICA: UM PROBLEMA PARA O ODONTÓLOGO}

Resumo: O presente trabalho visa criar uma consciencia entre os profissionais da saúde e nas instituições formadoras de dentistas, acerca do risco de perda de credibilidade na sociedade no exercicio profissional do odontólogo. Além disso apresenta as principais causas de reclamações dos pacientes que surgem a partir da ausencia da aplicação dos principios éticos.

Palavras chave: Bioética, odontologia, preceptos

Director de Estomatología. Comisión Nacional de Arbitraje Médico. México

Correspondencia: jtriana@conamed.gob.mx 


\section{Introducción}

La falta de aplicación de preceptos éticos en el ejercicio de la odontología, así como su ausencia en los currículos de las instituciones formadoras de profesionales de la salud bucal, ha generado mala práctica o deterioro de la imagen del odontólogo ante la sociedad.

La odontología es una disciplina relativamente joven que nació como parte de la medicina, de la cual no se ha podido separar de forma adulta para conseguir un lugar como una ciencia autónoma y respetable. Talvez, sigue arrastrando sus orígenes como una actividad técnico-artística que, en sus inicios, era practicada de forma elemental, principalmente por barberos y algunos médicos. Probablemente ha sido esta historia la que, hasta la fecha, le ha impedido crear la imagen y el estatus que le corresponde como parte de las ciencias médicas.

\section{Responsabilidad ética del odontólogo}

Tradicionalmente, la odontología ha estado más relacionada con aspectos técnicos del ejercicio de la profesión que con rasgos científicoéticos fundados en la vocación de quien la practica. No se ha considerado tan relevante la enseñanza de este tipo de valores dentro de una disciplina que ha sido identificada más con rasgos mercantiles y artesanales que morales. Tampoco se ha incorporado como parte fundamental en la formación de los recursos humanos que la eligen como medio de subsistencia económica, dejando de lado la responsabilidad que implica el trabajar directamente sobre "naturaleza viva”.

Por otro lado, es el mismo profesional de la salud bucal quien desconoce su ámbito éticolegal de responsabilidad, así como la manera en la que se encuentra inmerso en éste. Su compromiso no solamente es con la sociedad, sino que, en primera instancia, con él mismo como ser humano. Como tal, debe apegar su conducta no sólo a su inteligencia y voluntad, sino a los valores fundamentales inculcados en la familia y fomentados durante su formación escolar.

La falta de tratamiento específico del tema se debe a que, históricamente, se han ignorado las implicaciones que representa trabajar directamente sobre el paciente y la aplicación, también directa sobre él, de los instrumentos y la tecnología necesarios para el desarrollo de cualquier tratamiento estomatológico; siendo que, como principio constitucional, el cuidado de la salud es uno de los temas sociales prioritarios y se inscribe en el marco más amplio de la protección a la persona, por ser uno de sus derechos fundamentales(1).

Durante su ejercicio profesional, los cirujano dentistas deben afrontar situaciones con un gran contenido ético. En la mayoría de los casos los procedimientos involucran diagnósticos complejos y habilidades técnicas. La manera de aplicar estos criterios se basa tanto en el juicio del especialista como del paciente.

Cada recomendación lleva una gran dosis de ética y esto podrá cubrir o no las expectativas del paciente. En algunas ocasiones, las sugerencias generan inconformidad en los pacientes; en otras, sus pretensiones le parecen excesivas al odontólogo. La imagen que proyecte el dentista dependerá del modo como aborde estas situaciones, lo que influirá también en el resultado final del procedimiento.

En estas circunstancias, la ética sería de gran ayuda para tomar decisiones correctas. Desafortunadamente, mientras los avances tecnológicos y los cambios en las perspectivas sociales han incrementado los retos éticos inherentes a la odontología en los últimos veinte años, la respuesta por parte de las escuelas ha sido relativamente reciente(2). 
Lo anterior no significa que los odontólogos que ejercemos desde hace varios años estemos ajenos a los aspectos éticos de nuestra profesión. Empero, se deben adoptar medidas antes de que la práctica de la odontología pierda credibilidad por sospechas de una práctica deshumanizada y falta de reconocimiento profesional, entre otros muchos juicios negativos de los que sería objeto.

Un ejemplo de esta riesgosa situación se evidencia en la encuesta de opinión Gallup sobre ética y honestidad de las profesiones en Estados Unidos. Los dentistas deberían estar atentos a esta encuesta, ya que nuestra profesión se encuentra habitualmente entre los diez primeros puestos(3). Pese a que corresponde a un contexto ajeno al de los países latinoamericanos, debemos aceptar que las corrientes educativas, de mercadotecnia, de materiales e instrumental, de procedimientos, por mencionar sólo algunas de las muchas aportaciones, provienen de Estados Unidos de Norteamérica, lo que nos hace sensibles y vulnerables, al mismo tiempo, sobre las posibilidades de tener un desempeño muy similar al del citado país.

En 2000 los vendedores de coches fueron calificados como éticos por sólo un 7\% de los encuestados; los vendedores de seguros y los profesionales del marketing alcanzaron el 10\%; los periodistas un 16\%, mientras que los líderes sindicales, los vendedores de inmuebles y los jueces empataban con un $17 \%$. Una vez más, los dentistas se encontraban en la lista entre los diez primeros:

10. Agentes policiales, $55 \%$

9. Ingenieros, $56 \%$

8. Dentistas, $58 \%$

7. Profesores universitarios, $59 \%$

6. Religiosos, $60 \%$

5. Profesores de secundaria, $62 \%$

4. Médicos, $63 \%$
3. Veterinarios, $66 \%$

2. Farmacéuticos, $67 \%$

1. Enfermeros, $79 \%$ (3).

A la falta de reconocimiento de nuestra profesión dentro de la medicina, tendríamos que agregar que, en muchos países, pareciera que carecemos de una identidad universalmente aceptada. Ya no sólo en diferentes países o regiones se designa al profesional de la salud bucal de diferente manera, sino que dentro de uno solo existen diferentes denominaciones: basta con mencionar que en México tenemos registradas siete denominaciones diferentes.

Reforzando esta falta de identidad, la imagen que muchos tienen del dentista es la de aquel que sólo se dedica a "sacar y a tapar muelas”, restándole así todo el carácter científico a su formación.

¿Cómo nos gustaría que nos vieran nuestros pacientes? ¿Cómo nos gustaría llevar a cabo nuestro trabajo diario? ¿Qué clase de relación nos gustaría tener con nuestros colegas, con otros profesionales de la salud o con las mismas autoridades sanitarias? ¿Cómo se podría mejorar la atención odontológica en el ámbito institucional?

Sería interminable la lista de aspectos que podrían ser sometidos a un profundo análisis y que, imperiosamente, deben ser modificados. Pero, para ello, se requiere voluntad y decisión, y un trabajo en conjunto donde participen activamente asociaciones, colegios, instituciones educativas y autoridades. En tanto no se unifiquen criterios y continúen prevaleciendo intereses personales y de grupo, la odontología seguirá perdiendo reconocimiento ante la sociedad, con el riesgo de que, en un futuro no muy lejano, se nos califique como charlatanes. 


\section{La estomatología en el contexto mexicano}

En México contamos con la Comisión Nacional de Arbitraje Médico (CONAMED), organismo creado en 1996 con el propósito de resolver los conflictos suscitados entre los usuarios y los prestadores de servicios de salud de carácter público, privado y social, y para contribuir a mejorar la calidad y eficiencia de los servicios médicos en nuestro país. Su producto es el Modelo de Arbitraje Mexicano.

La misión de la Comisión es propiciar relaciones sanas entre los profesionales de la salud y sus pacientes, y representar una alternativa a los medios de impartir justicia.

En los últimos años, a partir del análisis de las inconformidades o quejas recibidas, se aprecia una disminución en la calidad de los servicios de la atención odontológica, lo que ha generado pérdida de confianza en la población. También se ha observado la aplicación, de manera inadecuada e indiscriminada, de procedimientos que promueven expectativas falsas o inalcanzables y, sobre todo, el incumplimiento y desconocimiento, parcial o total, del marco normativo que regula el ejercicio de la profesión, así como la matización de una ética profesional deficiente.

Lo anterior ha provocado la aparición de seguros de responsabilidad profesional, aplicación de la medicina defensiva y, en muchos casos, se ha detectado también la existencia de mala práctica. Este riesgo se incrementa al no contar con medios de control o supervisión en gran número de consultorios privados de atención odontológica, y en los que el ejercicio de la profesión puede eventualmente efectuarse por personal no calificado o carente de título universitario.

Las irregularidades con mayor incidencia y frecuencia son, en primer lugar, la falta de co- municación entre el profesional de la salud bucal y el paciente: maltrato al paciente, el profesional no explica en términos accesibles para el usuario, no enfatiza el alcance y las limitaciones del tratamiento en cuestión, no informa del costo y de la relación riesgo/beneficio de la atención (posibilidad de fracaso del procedimiento otorgado), incurre en inexactitudes e imprecisiones, delega responsabilidades y modifica convenios en cuanto a modo, tiempo y costo de la atención brindada.

En segundo término, existe la tendencia a despertar falsas expectativas en los pacientes; el uso y manejo equivocados de materiales y procedimientos no indicados, así como tratamientos simulados, pretensiones clínicamente inalcanzables y técnicas clínicas inexpertas.

En tercer lugar, el incumplimiento de obligaciones:

- De medios: ausencia de expediente clínico, omisión de historia clínica y consentimiento válidamente informado (que anula el sustento legal de las declaraciones clínicas del paciente), carencia de auxiliares diagnósticos (estudios radiográficos, de gabinete, referencia de interconsulta, inadecuado manejo farmacológico), así como la deficiencia de un pronóstico y plan de tratamiento.

- De seguridad: exponer al paciente a riesgos innecesarios, no salvaguardando la integridad física, clínica y psicológica del usuario.

- De resultados: insatisfacción del paciente ante los ofrecimientos prometidos a priori por el facultativo, tratamientos exageradamente prolongados y costosos.

En cuarto lugar, el desconocimiento, por parte del profesional de la salud bucal, de la 
Ley General de Salud y las Normas Oficiales Mexicanas que regulan el ejercicio de la profesión odontológica, así como la relación con los pacientes.

En quinto término, anteponer las técnicas rehabilitatorias mutilantes a las técnicas preventivas conservadoras de calidad.

En sexto lugar, una ética profesional deficiente, expresada en la prevalencia de los intereses del profesional sobre los del paciente, ausencia de actualización profesional, ejercicio indebido del menester odontológico (ejercicio de la profesión sin las acreditaciones respectivas) y la práctica de una medicina bucal defensiva.

Cabe enfatizar que, contrariamente a todas estas irregularidades, el diagnóstico, pronóstico y plan de tratamiento constituyen la piedra angular para otorgar al paciente óptimas condiciones de salud estomatológica e integral, y que son los fundamentos de la profesión odontológica(4).

Ante esta perspectiva, surge la imperiosa necesidad de que, como primera obligación, el gremio odontológico conozca cuáles son las principales causas de inconformidad y las irregularidades encontradas en la atención odontológica que se brinda a la población, ya sea en el ámbito público o privado.

De manera aleatoria, lo anterior nos obliga a diseñar estrategias para mejorar la calidad de la práctica odontológica, que involucren de manera directa a los profesionales y no únicamente a los participantes en la formación de nuevos recursos humanos.

Por tanto, los odontólogos debemos reflexionar sobre la práctica contemporánea de la estomatología en nuestros países y efectuar diversos planteamientos, que van desde retomar los valores éticos inculcados durante nuestra formación profesional -a través de reuniones colegiadas y de discusión- hasta la aportación de experiencias propias, con la finalidad de incidir en la mejoría de la calidad de nuestro ejercicio.

Es importante destacar que nuestro país cuenta con regulaciones de la Ley General de Salud y Normas Oficiales Mexicanas, que deben difundirse entre el gremio estomatológico institucional y privado. Asimismo, se señala la urgente necesidad de orientar al paciente en cuanto al conocimiento de sus derechos y obligaciones ante una rehabilitación estomatológica integral y, por supuesto, la inherente optimización en la calidad de los servicios brindados por parte del profesional de la salud.

A partir del análisis de las quejas recibidas, la CONAMED ha elaborado recomendaciones para mejorar la práctica de la odontología, acordes con la legislación de nuestro país(5):

- Fomentar las estrategias preventivas de manera intensiva para evitar la aparición prematura de enfermedades estomatológicas.

- Practicar todo acto estomatológico diagnóstico, resolutivo y rehabilitatorio en un marco legal que asegure el cumplimiento jurídico de su proceder.

- Favorecer y promover la comunicación respetuosa y permanente entre el profesional de la salud bucal, el paciente y/o sus familiares o representantes legales.

- Integrar un expediente que incluya una historia clínica, así como un consentimiento válidamente informado.

- Determinar un diagnóstico oportuno, así como un pronóstico y plan de tratamiento acordes con las bases éticas y científicas. 


\section{Conclusiones}

- La odontología ha sido identificada tradicionalmente más con aspectos técnicos que con aspectos científicos.

- Los odontólogos desconocemos la responsabilidad que se genera al no aplicar conceptos éticos y legales en nuestro ejercicio profesional.

- Diariamente, el cirujano-dentista debe enfrentar situaciones que requieren la aplicación de conceptos éticos.

- Se precisa enfatizar más en todas las instancias involucradas con la odontología, tanto formadoras de recursos como de atención pública y privada, sobre la aplicación de conceptos éticos.

- Se ha detectado una disminución en la calidad de los servicios odontológicos y la pérdida de confianza por parte de los usuarios de este servicio.

- Gran parte de los problemas identificados en el ámbito de la relación clínica entre cirujano dentista y paciente se deriva de la falta de información y fallas en la comunicación.

- El acto odontológico se rige por los mismos principios científicos, éticos y legales que el acto médico, predominando el aspecto ético.

\section{Referencias}

1. Weingarten C. Responsabilidad por prestaciones odontológicas. Buenos Aires: Astrea; 1997.

2. Rule JT, Veatch RM. Ethical questions in Dentistry. Illinois: Quintessence Publishing Co. Inc; 1993.

3. Carlson DK. Nurses remain at top of honesty and ethics poll (poll analyses). Gallup Organization Web site. Available at: www.gallup.com/poll/releases/pr001127.asp Accessed June 22, 2001.

4. Christensen GJ. Elective vs. mandatory care. JADA 2000; 131: 1496-1498.

5. Recomendaciones para mejorar la práctica de la Odontología. CONAMED 2003; 8(1). 